Abstracta Iranica Iranica

Revue bibliographique pour le domaine irano-aryen

Volume 26 | 2005

Comptes rendus des publications de 2003

\title{
A New Etymological Vocabulary of Pashto. Wiesbaden, Reichert, 2003, 140 p.
}

\section{Daniel Septfonds}

\section{(2) OpenEdition \\ 1 Journals}

Édition électronique

URL : http://journals.openedition.org/abstractairanica/3688

ISSN : 1961-960X

\section{Éditeur :}

CNRS (UMR 7528 Mondes iraniens et indiens), Éditions de l'IFRI

\section{Édition imprimée}

Date de publication : 15 mai 2005

ISSN : 0240-8910

\section{Référence électronique}

Daniel Septfonds, «A New Etymological Vocabulary of Pashto. Wiesbaden, Reichert, 2003, 140 p. »,

Abstracta Iranica [En ligne], Volume 26 | 2005, document 46, mis en ligne le 15 décembre 2005,

consulté le 25 septembre 2020. URL : http://journals.openedition.org/abstractairanica/3688

Ce document a été généré automatiquement le 25 septembre 2020.

Tous droits réservés 


\section{A New Etymological Vocabulary of Pashto. Wiesbaden, Reichert, 2003, $140 \mathrm{p}$.}

Daniel Septfonds 
1 A New Etymological Vocabulary of Pashto ('NEVP') est une seconde version, augmentée et repensée, d'un ouvrage publié par G. Morgenstierne en 1927 : An Etymological Vocabulary of Pashto, Oslo, 120 p. ('EVP').

2 Au début des années 70, G. Morgenstierne, désireux de rassembler ses données relatives au pashto et de remanier ' $E V P$ ', engage une collaboration avec Neil MacKenzie. Celle-ci durera jusqu'à la mort de Morgenstierne - en 1978. Le chantier sera abandonné pour dix ans, jusqu'à ce que J. Elfenbein à partir de 1988 offre son aide à MacKenzie. La collaboration s'achève en 1990 sans avoir abouti. Nouvel abandon, dix ans encore. MacKenzie décède en 2001. Parmi les ouvrages qu'il laisse inachevés, ce vocabulaire. Elfenbein décide alors de se remettre à la tâche avec l'aide de N. Sims-Williams qui assume les fonctions éditoriales. P. O. Skjærvø relira l'ensemble et fera de nombreuses suggestions.

Dans l'avant-propos (pp. V-VIII), après avoir présenté la genèse de l'ouvrage, Elfenbein précise que la visée de celui-ci est purement étymologique et renvoie le lecteur plus particulièrement soucieux de phonologie historique à P. O. Skjærvø 1989 («Pashto », Compendium Linguarum Iranicarum, Wiesbaden, pp.384-410). Suit une liste d'abréviations (pp.1-4), des références bibliographiques (pp. 5-6), puis le vocabulaire étymologique proprement dit (pp. 7-106), et un index (pp. 107-140).

4 Le nombre d'entrées du vocabulaire étymologique est plus élevé que dans 'EVP' mais provient touj ours, pour l'essentiel, de Morgenstierne. On doit à Elfenbein de nombreux ajouts principalement Waneci. Des phonèmes qui n'avaient droit à aucune entrée en sont pourvus. Ainsi du /d/ et du / $\mathrm{t} /$ rétroflexes par exemple. L'index permet d'accéder, à partir de n'importe laquelle des entrées provenant des langues citées dans l'ouvrage, à la forme pashto telle qu'elle est donnée en vedette dans le vocabulaire.

5 L'ouvrage était attendu, il est paru. C.r. complet dans Studia Iranica.

INDEX

Thèmes : 2.2. Langues vivantes et dialectes

Mots-clés : linguistique, vocabulaire étymologique, langue pashto

Keywords : linguistics, etymological vocabulary, Pashto language

\section{AUTEURS}

\section{DANIEL SEPTFONDS}

INaLCO - Paris 